\title{
Mobilisation of lipophilic pollutants from blubber in northern elephant seal pups (Mirounga angustirostris) during the post-weaning fast
}

\author{
Caroline Louis ${ }^{\mathrm{a}}$, Alin C. Dirtu ${ }^{\mathrm{b}, \mathrm{c}}$, Marie Stas ${ }^{\mathrm{a}}$, Yves Guiot ${ }^{\mathrm{d}}$, Govindan Malarvannan ${ }^{\mathrm{b}}$, \\ Krishna Das ${ }^{\mathrm{e}}$, Daniel P. Costa ${ }^{\mathrm{f}}$, Daniel E. Crocker ${ }^{\mathrm{g}}$, Adrian Covaci ${ }^{\mathrm{b}}$, Cathy Debier ${ }^{\mathrm{a}, *}$ \\ a Institut des Sciences de la Vie, UCLouvain, Croix du Sud 2/L7.05.08, 1348 Louvain-la-Neuve, Belgium \\ ${ }^{\mathrm{b}}$ Department of Pharmaceutical Sciences, Toxicological Center, Campus Drie Eiken, Universiteit Antwerpen, Universiteitsplein 1, 2610 Wilrijk, Belgium \\ ' Department of Chemistry, "Al. I. Cuza" University of Iasi, 700506 Iasi, Romania \\ ${ }^{\mathrm{d}}$ Department of Pathology, Faculty of Medicine, UCLouvain, Brussels, Belgium \\ e Laboratoire d'Océanologie, MARE Center B6c, Université de Liège, 4000 Liège, Belgium \\ ${ }^{\mathrm{f}}$ Ecology and Evolutionary Biology Department, University of California Santa Cruz, 100 Shaffer Rd, Santa Cruz, CA 95060, USA \\ ${ }^{\mathrm{g}}$ Department of Biology, Sonoma State University, 1801 East Cotati Ave, Rohnert Park, CA 94928, USA
}

\section{A R T I C L E I N F O}

\section{Article history:}

Received 24 January 2014

Received in revised form

14 March 2014

Accepted 15 April 2014

Keywords:

Northern elephant seal

PCBs

PBDEs

Pesticides

Blubber

Serum

\begin{abstract}
A B S T R A C T
Northern elephant seals (NES) (Mirounga angustirostris) from the Año Nuevo State Reserve (CA, USA) were longitudinally sampled during the post-weaning fast in order to study the mobilisation and redistribution of various classes of persistent organic pollutants (POPs), such as polybrominated diphenyl ethers (PBDEs), polychlorinated biphenyls (PCBs), dichlorodiphenyldichloroethylene ( $p, p^{\prime}$-DDE) and hexachlorobenzene (HCB) between blubber and blood. Inner and outer blubber layers were analysed separately. Organohalogenated compounds were detected in all blubber samples in the decreasing order of their concentrations: $p, p^{\prime}$-DDE $>$ PCBs $\gg \mathrm{HCB}>$ PBDEs. The concentrations of all studied compounds were homogeneously distributed in the blubber layer at early fast, since the concentrations of POPs were statistically not different in the inner and outer layers. With the progression of the fast, the concentrations of PBDEs, PCBs and $p, p^{\prime}$-DDE increased more sharply in inner blubber than in outer blubber. As a result, their levels became significantly higher in inner blubber as compared to outer blubber at late fast. The rise of pollutant concentrations in blubber might result from a less efficient mobilisation than triglycerides and/or a reuptake by adipocytes of some of the pollutants released into the circulation. The mobilisation of pollutants from blubber was higher at late fast. An increase of pollutant concentrations was observed in serum between early and late fast. Lower halogenated congeners (i.e. tetra-CBs) were present in higher proportions in serum, whereas the higher halogenated congeners (i.e. hepta-CBs) were mainly found in the inner and outer blubber layers. The transfer ratios of both PBDEs and PCBs from inner blubber to serum decreased with the number of chlorine and bromine atoms. In addition, the distribution of both types of compounds between serum and blubber was strongly influenced by their lipophilic character ( $\log K_{\text {ow }}$ values), with more lipophilic compounds being less efficiently released from blubber to serum.
\end{abstract}

(c) 2014 Elsevier Inc. All rights reserved.

\section{Introduction}

Persistent organic pollutants (POPs), such as polychlorinated biphenyls (PCBs), organochlorine pesticides (e.g. dichlorodiphenyltrichloroethane and its metabolites (DDTs), hexachlorobenzene (HCB)) and polybrominated diphenyl ethers (PBDEs), have captured the attention of scientists since several decades. They accumulate in living organisms and can biomagnify in aquatic and terrestrial food webs (Covaci et al., 2002a; Jürgens et al., 2013;

\footnotetext{
* Corresponding author.

E-mail address: cathy.debier@uclouvain.be (C. Debier).
}

Letcher et al., 2010; Vanden Berghe et al., 2012). Marine mammals are highly exposed to these fat-soluble chemicals because of their high trophic-chain position and their long life spans. POPs are preferentially accumulated in the adipose tissue (Debier et al. 2003, 2006; Vanden Berghe et al., 2012), but also in various compartments such as blood, liver and brain (Covaci et al., 2002b; de Wit, 2002; Mossner et al., 1994; Weijs et al., 2009). The presence of POPs might generate an insidious threat, as they are known to exert negative effects such as immunotoxicity and endocrine disruption (Darnerud, 2008; Ross, 2002; Ylitalo et al., 2005). Some POPs (e.g., PBDEs, PCBs or $p, p^{\prime}$-dichlorodiphenyldichloroethylene ( $p, p^{\prime}$-DDE)) may interfere with the metabolism and blood transport of thyroid hormones and vitamin A (Das et al., 
2006; Debier et al., 2005b; Vanden Berghe et al., 2010), which are essential to ensure proper development of the pup.

During fasting periods, which are very common in the life cycle of marine mammals, lipophilic molecules, such as POPs, are liberated from the blubber into the blood circulation (Debier et al., 2003, 2006; Vanden Berghe et al., 2012). Among marine mammal species, northern elephant seals (NES) exhibit some of the longest durations of natural fast (e.g. during reproduction, moulting, post-weaning and lactation). During these periods, they mobilise the triglycerides stored in the blubber in order to provide energy and to maintain homoeostasis of the body. This phenomenon induces the combination of two effects: the release of lipophilic pollutants into the circulation as well as the increase of their concentration in the blubber, possibly because POPs are less efficiently mobilised from blubber than lipids (Debier et al., 2006; Vanden Berghe et al., 2012). During lactation, high levels of POPs are transferred from the body stores of fasting females to the pups through the consumption of lipid-rich milk (Debier et al., 2006, 2012; Vanden Berghe et al., 2012). Upon weaning, NES pups fast and mobilise primarily lipids from their large amount of blubber. Previously, we have investigated the dynamics of mobilisation of PCBs from blubber to blood during the post-weaning fast of NES (Debier et al., 2006). PCBs appeared to concentrate in the inner part of the blubber at the beginning of the fast, before being released in high amounts in the circulation at the end of the fast. This pattern has not been investigated for other POPs (e.g. PBDEs, DDT and HCB). In general, little is known about the mobilisation of pollutants during energy deprivation stages and particularly in young and fasting animals.

In this paper, we describe the dynamics of mobilisation of POPs (PBDEs, PCBs, HCB and $p, p^{\prime}$-DDE) from the blubber to the blood circulation of NES pups throughout their post-weaning fast. Blubber was differentiated into inner and outer layers. Samples were collected on free-ranging animals from the Año Nuevo colony from January to April 2010, caught four times throughout the post-weaning fast. Individuals from the same colony were already sampled in 2002 to provide information on the dynamics of PCBs throughout the post-weaning fast of NES pups (Debier et al., 2006).

\section{Material and methods}

\subsection{Seal sampling}

The sampling took place at Año Nuevo State Reserve, CA, USA $\left(37^{\circ} 06^{\prime} 30^{\prime \prime} \mathrm{N}\right.$ $122^{\circ} 20^{\prime} 10^{\prime \prime} \mathrm{W}$ ) from January to April 2010, under the National Marine Fisheries Service Marine Mammal Permit \#87-1743-05. Twenty-two free ranging pups were sampled at 1-, 4- 7- and 10-week post-weaning (later also assigned early, mid, late and very late fast, respectively). Each animal was specifically marked with dye and was followed by observing the colony each day. NES pups were initially immobilised with an intramuscular injection of Telazol at $\sim 1 \mathrm{mg} / \mathrm{kg}$ of estimated body mass and sedation was maintained through subsequent intravenous injections of Ketamine (all drugs were from Fort Dodge Animal Health, Fort Dodge, IA, USA) as needed. At each capture, blood was collected from the extradural vein into Vacutainer serum tubes (Becton-Dickinson, Erembodegem, Belgium). Samples were centrifuged at $1300 \times \mathrm{g}$ for $15 \mathrm{~min}$ at $4{ }^{\circ} \mathrm{C}$ and serum was aliquoted into microtubes and stored at $-20^{\circ} \mathrm{C}$ until analysis. At weeks 1,4 and 7, blubber samples were taken after subcutaneous injection of lidocaine for local anaesthesia. A blubber biopsy extending the full depth of the blubber layer was taken in the lateral pelvis area using 6-mm biopsy punches (Miltex, Help Medical, Paris, France) and stored in aluminium foil at $-20{ }^{\circ} \mathrm{C}$ until analysis. This biopsy is considered as a representative sample since the anatomical area chosen for blubber collection has little influence on pollutant content (Debier et al., 2006; Severinsen et al., 2000).

\subsection{POP analyses}

Blubber biopsies were cut into three equal parts. Inner (closest to the muscle) and outer (closest to the skin) layers were analysed separately. In all blubber and serum samples, 6 PBDEs (IUPAC numbers: BDE-28, $-47,-99,-100,-153$ and -154),
30 PCB congeners (IUPAC numbers: CB-28, $-47,-49,-52,-74,-95,-99,-101,-105$, $-110,-118,-128,-138,-146,-149,-151,-153,-156,-170,-171,-172,-174,-177,-180$, $-183,-187,-194,-199,-206$ and -209$), p, p^{\prime}-$ DDE and HCB were targeted.

Details of the preparation, extraction, clean-up and quality control for the blubber samples are described in Covaci et al. (2008). Briefly, inner and outer blubber were weighed $(\sim 150 \mathrm{mg})$, mixed with anhydrous $\mathrm{Na}_{2} \mathrm{SO}_{4}$ and spiked with internal standards (CB-143 and BDE-77) in each sample. Pollutant and lipid extractions were carried out by automated Soxhlet method with $n$-hexane/acetone (3:1, v:v). Samples were then loaded on acid silica ( $44 \% \mathrm{H}_{2} \mathrm{SO}_{4}$, w:w) cartridge in order to clean them up and were eluted with $n$-hexane and dichloromethane. Finally, solvents were evaporated and purified extracts were reconstituted in iso-octane.

Serum samples were analysed as reported in Weijs et al. (2009) and Vanden Berghe et al. (2012). In brief, internal standards (CB-143, $\varepsilon$-HCH and BDE-77) were added at $1.5 \mathrm{~mL}$ serum followed by deionized water and formic acid. The mixture was sonicated for $20 \mathrm{~min}$ and loaded on solid-phase-extraction (SPE) cartridge (200 mg, Oasis HLB, Waters, Milford, MA). Pollutants were eluted with dichloromethane/methanol (1:1, v:v). Extracts were then dried and reconstituted in hexane. PBDEs, PCBs, $p, p^{\prime}$-DDE and HCB were eluted with $n$-hexane from a silica SPE cartridge (500 mg, VWR, Belgium) topped with acidified silicagel $\left(44 \% \mathrm{H}_{2} \mathrm{SO}_{4}\right.$, $\mathrm{w}: \mathrm{w})$. Samples were then evaporated and reconstituted in iso-octane.

All compounds were measured with an Agilent 6890 gas chromatograph coupled with a 5973 mass spectrometer system (GC-MS). All analytical details as well as performed quality assurance and quality control are available in Vanden Berghe et al. (2012).

\subsection{Lipid determination}

Lipid content in blubber was performed gravimetrically after the automated Soxhlet extraction (see Section 2.2) and was used to normalise contaminant data. For serum, different lipid classes (total cholesterol, phospholipids, triglycerides and non-esterified fatty acids (NEFAs)) were measured using in vitro enzymatic colorimetric method assays (Wako and Diasys, Sopachem, Eke, Belgium) following the manufacturer's instructions. The total lipids of serum correspond to the sum of the different targeted lipid classes.

\subsection{Blubber morphometry}

One blubber biopsy was taken as described above on three different animals, sampled at 1-, 4- and 7-week post-weaning, respectively. Each sample was fixed in $4 \%$ buffered paraformaldehyde solution and then routinely embedded in paraffin. Five-micrometer-thick slices were processed. Sections were counterstained with hematoxylin eosine (Sigma-Aldrich, Bornem, Belgium). The mean relative proportion of adipocytes was estimated by a point-counting technique. Equipment consisted of an inverted microscope $(20 \times$ magnification, Axiostar Zeiss, Zeiss, Zaventem, Belgium) and a video camera (AxioCam MRc Zeiss). Each adipocyte was manually delineated and 700-1200 cells per condition were assessed. The surface area of adipocytes $\left(\mu \mathrm{m}^{2}\right)$ was calculated using an image analyser software (AxioVision 4.7 .1 ; 08-2008). Final results are expressed as distribution of cell area.

\subsection{Statistics}

Data were log transformed to achieve normality. For pollutant concentrations below the limit of quantification (LOQ), a LOQ $\times$ detection frequency value was assigned (see Supplementary Information). Statistical analyses were conducted using SAS 9.3 software (SAS Institute Inc., Cary, USA). Linear mixed models were used to test the differences in pollutant levels and profiles as well as lipid levels throughout the post-weaning fast periods within a same tissue. Animal ID was modelled as a random effect. Furthermore, pollutant and lipid concentrations were analysed using one-way ANOVA with a Tukey test for each capture in order to compare the levels between tissues. The level of statistical significance was set at $p \leq 0.05$ for all analyses. Results are presented as means \pm SEM.

Regarding morphometry, statistical analyses were conducted using a Kolmogorov-Smirnov test to compare two distributions of adipocyte profile area (SAS 9.3 software). Results of distribution of cell area are presented in percentage and by class of adipocyte size.

\section{Results}

\subsection{Biometry of NES}

At early fast, the mean mass of NES was $128 \pm 3 \mathrm{~kg}$ with a mean body mass index (BMI) of $59 \pm 1 \mathrm{~kg} / \mathrm{m}^{2}$. Animals lost weight throughout the fast to reach $96 \pm 2 \mathrm{~kg}$ with a BMI of $42 \pm$ $1 \mathrm{~kg} / \mathrm{m}^{2}$ after 7 weeks of fast (Table 1 ). The sex ratio of targeted NES was $1: 1$ 
Table 1

Biometry of northern elephant seals throughout the post-weaning fast period; mean \pm SEM (range).

\begin{tabular}{|c|c|c|c|c|c|}
\hline & $n$ & Post-weaning fast day [day] & Mass [kg] & Standard length $[\mathrm{cm}]$ & BMI $\left[\mathrm{kg} / \mathrm{m}^{2}\right]$ \\
\hline Week 1 & 22 & $1 \pm 1(0-4)$ & $128 \pm 3(92-148)$ & $146 \pm 1(131-156)$ & $59 \pm 1(48-69)$ \\
\hline Week 4 & 22 & $23 \pm 1(22-25)$ & $110 \pm 2(77-125)$ & $147 \pm 2(130-159)$ & $51 \pm 1(41-63)$ \\
\hline Week 7 & 22 & $46 \pm 2(44-50)$ & $96 \pm 2(66-115)$ & $151 \pm 1(132-160)$ & $42 \pm 1(38-50)$ \\
\hline Week 10 & 14 & $61 \pm 2(58-66)$ & - & - & - \\
\hline
\end{tabular}

Sex ratio (female:male $)=1: 1$.

\subsection{Changes of lipid contents in blubber and serum}

Total lipid content of outer blubber increased during the first half of the fast $(p<0.001)$ and remained stable between weeks 4 and 7 ( $p=0.282$ ) (Fig. 1A). In inner blubber, lipid content did not vary between weeks 1 and $4(p=0.261)$ and then decreased slightly between weeks 4 and $7(p=0.030)$, reaching lipid concentration similar to early fast $(p=0.475)$ (Fig. 1A). The lipid percentages were significantly higher in the inner blubber than in the outer blubber $(p=0.006$ at week 1 and $p<0.001$ at week 4$)$, except at week $7(p=0.746)$.

Morphometric analysis of one blubber biopsy showed that the proportion of small adipocytes (cell area $<2800 \mu \mathrm{m}^{2}$ ) tended to increase during the fast in both layers whereas the proportions of mid-size adipocytes $\left(2800 \mu \mathrm{m}^{2}<\right.$ cell area $\left.<5600 \mu \mathrm{m}^{2}\right)$ as well as large-size adipocytes $\left(5600 \mu \mathrm{m}^{2}<\right.$ cell area $\left.<8400 \mu \mathrm{m}^{2}\right)$ tended to decrease (Fig. 1B). The size of each class of adipocytes is shown in Fig. 1C. The 2-sample Kolmogorov-Smirnov test highlighted a significant difference in the distribution of adipocyte area throughout the fast within the inner $(0.001<p<0.017)$ and outer blubber $(0.001<p<0.036)$ (Fig. 1B). Furthermore, these distributions were also significantly different between the two layers for a given capture $(p<0.001$ at week $1, p=0.007$ at week $4, p<0.001$ at week 7) (Fig. 1B).

The total lipids of serum were formed by phospholipids $(54 \pm 3 \%)$, total cholesterol $(32 \pm 3 \%)$, triglycerides $(9 \pm 3 \%)$ and NEFAs $(5 \pm 2 \%)$ (Table S1 in the Supplementary Information). The total lipid content in serum increased sharply between weeks 1 and $4(p<0.001)$, then tended to stabilise between weeks 4 and $7(p=0.051)$ and remained constant between weeks 7 and 10 $(p=0.558)$ (Fig. 2A). NEFAs, which result from the lipolytic activity and thus, the hydrolysis of triglycerides mobilised from the blubber, doubled between weeks 1 and 10 ( $p<0.001$ ) (Fig. 2B).

\subsection{Changes of POPs in blubber}

\subsubsection{PBDES}

Total PBDE concentrations were similar in inner and outer blubber at the beginning of the fast and at mid fast ( $p=0.895$ and $p=0.155$, respectively). On the other hand, concentrations became significantly higher in the inner layer as compared to the outer layer at late fast $(p=0.003)$. The appearance of a difference at late fast resulted from variations in the dynamics of total PBDEs across the fast between both layers. Indeed, while total PBDE content increased significantly in the inner blubber throughout the fast $(p<0.001)$, it remained stable between weeks 1 and $4(p=0.963)$ and only increased between weeks 4 and $7(p<0.001)$ in outer blubber. Thus, the magnitude of the increase was much greater in inner blubber than in outer blubber (Fig. 3A).

Among PBDE congeners that have been targeted, BDE-28 and BDE-153 were detected only in a few samples of NES pups (Table $\mathrm{S} 2$ in the Supplementary Information). Because of their low detection rates, no statistical test was performed on these congeners. BDE-47 was the major congener representing $82 \pm 2 \%$. Within the outer blubber, the concentrations of BDE-47 and -100
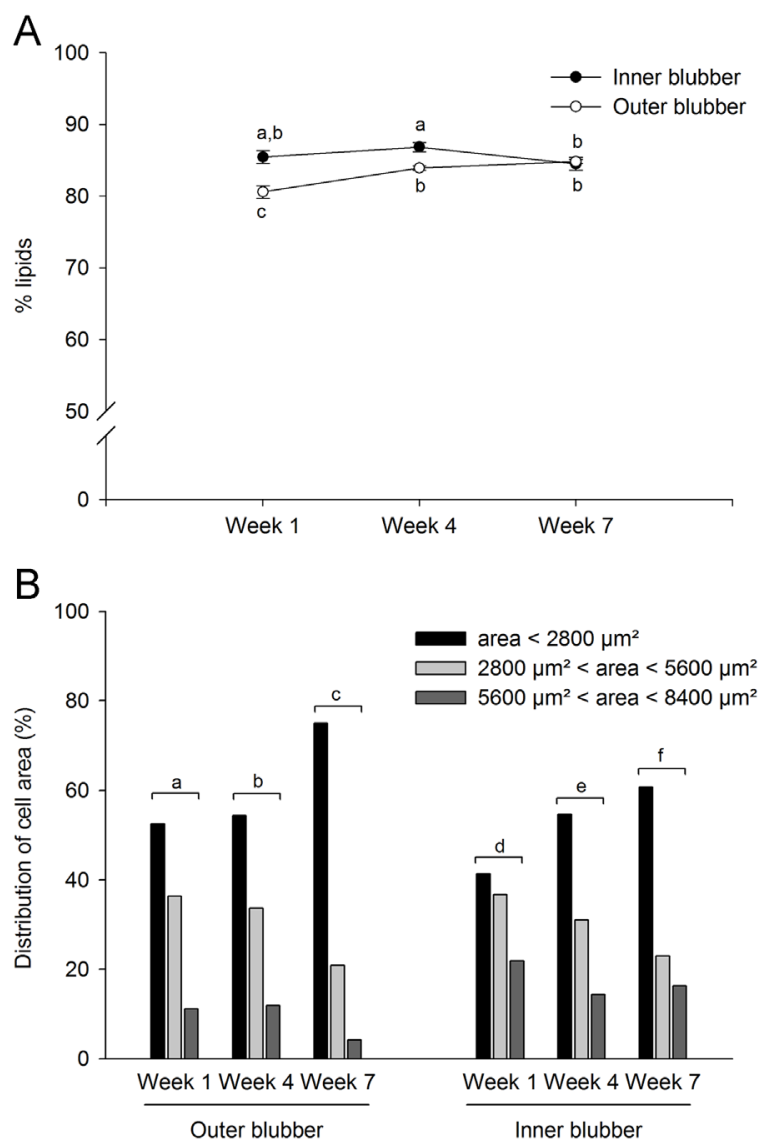

C

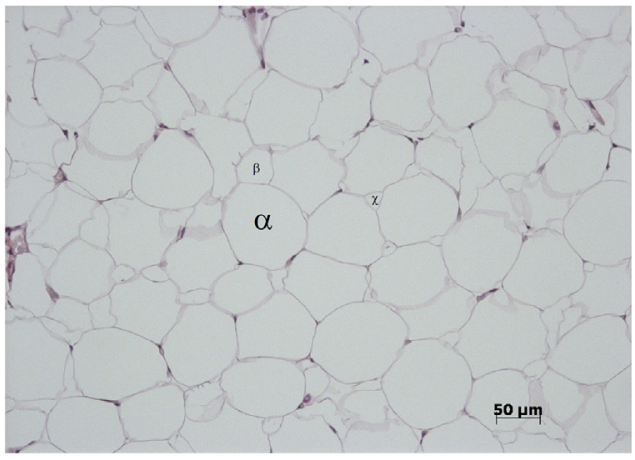

Fig. 1. Overall changes of lipids throughout the post-weaning fast of northern elephant seal pups in inner and outer blubber layers (weeks 1, 4 and 7). (A) Lipid levels in blubber (mean levels \pm SEM). Values with different symbols are significantly different within a defined layer as well as for a considered period $(p \leq 0.050)$ (B) Distribution of adipocyte area arbitrarily classified in three categories of size. The area of small-size adipocytes was lower than $2800 \mu \mathrm{m}^{2}$. The area of mid-size adipocytes was between $2800 \mu \mathrm{m}^{2}$ and $5600 \mu \mathrm{m}^{2}$ and the area of large-size adipocytes, between $5600 \mu \mathrm{m}^{2}$ and $8400 \mu \mathrm{m}^{2}$. Distributions that do not share same letter show significant differences $(p \leq 0.050)$. (C) Histological slide of northern elephant seal adipose tissue (light microscopy). Symbols illustrate the three categories of adipocyte sizes: $\alpha$ for large-size class, $\beta$ for mid-size class and $\chi$ for small-size class. 
A

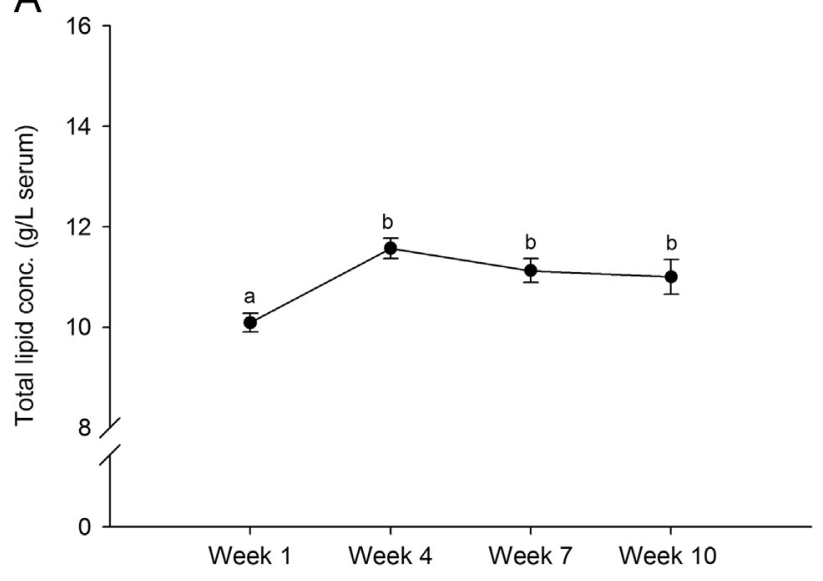

B

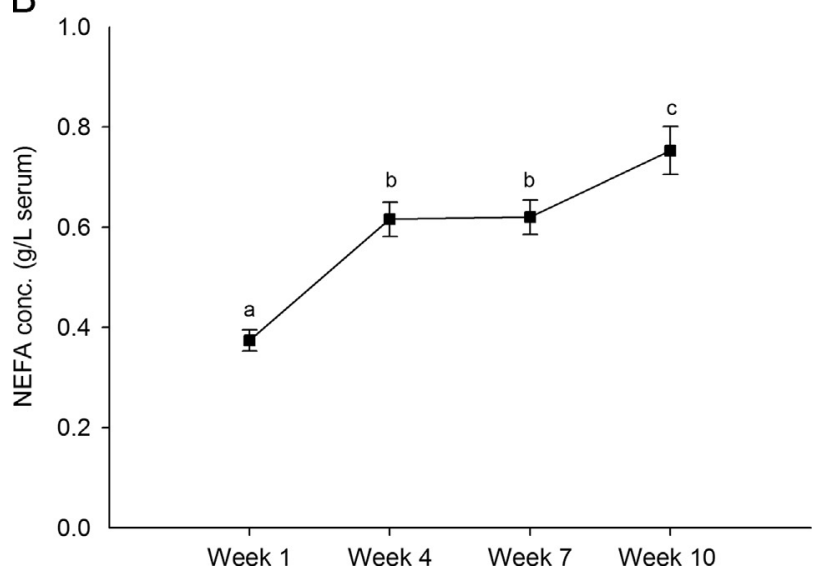

Fig. 2. Overall changes of lipids throughout the post-weaning fast of northern elephant seal pups in serum (weeks 1, 4, 7 and 10). Total lipid concentration $($ mean $\pm \mathrm{SEM})(\mathrm{A})$ and non-esterified fatty acid (NEFA) concentrations (mean \pm SEM) (B) measured in the serum, expressed in $\mathrm{g} / \mathrm{L}$. Values with different symbols are significantly different $(p \leq 0.050)$.

increased significantly between weeks 1 and $7(p<0.001)$, while BDE-99 and -154 remained stable over the fast $(0.361<$ $p<0.647$ ) (Table 2). Within the inner blubber, the concentrations of BDE-47, $-99,-100$ and -154 rose significantly throughout the fast $(0.001<p<0.015)$ (Table 2$)$.

\subsection{2. $P C B S$}

Total PCB concentrations were statistically similar in inner and outer blubber at weeks 1 and 4 of fast $(p=0.608$ and $p=0.132$, respectively). On the other hand, concentrations became significantly higher at week 7 in the inner layer as compared to the outer layer $(p<0.001)$. Similarly to PBDEs, the increase of total PCBs throughout the fast was sharper in inner blubber as compared to outer blubber $(p<0.001$ in inner blubber and $0.006<p<0.022$ in outer blubber) (Fig. 3B).

Within PCB groups, PCB-206, the only nona-CB targeted in this study, and CB-209, the deca-CB, were not detected in any sample. As a result, those congeners were not included in statistical analyses (Table S3 in Supplementary Information). In both blubber layers, the main classes were hexa-CBs (PCB-128, -138, -146, $-149,-151,-153$ and -156$)$ followed by penta-CBs (PCB-95, -99, $-101,-105,-110$ and -118 ), hepta-CBs (PCB-170, -171, -172, -174, $-177,-180,-183,-187$ ), tetra-CBs (PCB-47, $-49,-52,-74)$, tri-CBs (PCB-28) and octa-CBs (PCB-194 and -199) across the fasting period. $\mathrm{PCB}-153$ formed almost one half of hexa-CB congeners
( $42 \pm 2 \%$ in outer blubber and $42 \pm 1 \%$ in inner blubber) and PCB138 , one third $(32 \pm 2 \%$ in outer blubber and $33 \pm 2 \%$ in inner blubber). In the class of penta-CBs, two congeners were predominant: PCB-99 ( $30 \pm 5 \%$ in outer and inner blubber layers) and PCB118 ( $38 \pm 4 \%$ in outer blubber and $38 \pm 3 \%$ in inner blubber). Two congeners were important in the group of hepta-CBs: PCB-180 $(30 \pm 1 \%$ in outer blubber and $30 \pm 2 \%$ in inner blubber) and PCB187 ( $31 \pm 3 \%$ in outer blubber and $29 \pm 3 \%$ in inner blubber). Within the class of tetra-CBs, PCB-74 (59 $\pm 4 \%$ in outer blubber and $56 \pm 1 \%$ in inner blubber) followed by PCB-52 (18 $\pm 5 \%$ in outer blubber and $18 \pm 4 \%$ in inner blubber) were the most representative congeners. Finally, the class of octa-CBs were mainly composed of PCB-199 (93 $\pm 2 \%$ in outer blubber and $87 \pm 3 \%$ in inner blubber).

In the outer blubber, concentrations of tri-CBs remained stable between early and late fast $(p=0.216)$, whereas the concentrations of tetra-, penta-, hexa-, hepta- and octa-CBs increased $(p<0.001)$ (Table 2). In the inner blubber, similar dynamics were observed for tri-CBs $(p=0.411)$ and the other congener classes $(p<0.001)$ (Table 2). The magnitude of the increase of concentration between early and late fast varied among PCB classes, especially in inner blubber. Indeed, the rises were significantly higher for octa- and hepta-CBs than for hexa- and penta-CBs $(0.001<p<0.018)$, which were themselves significantly higher than for tetra- and tri-CBs $(p<0.001)$. On the contrary, the rises between early and late fast were similar between octa- and hepta-CBs $(p=0.078)$, hexa- and penta-CBs $(p=0.330)$ and tetra- and tri-CBs $(p=0.648)$.

\subsection{3. $p, p^{\prime}-D D E$}

$p, p^{\prime}$-DDE contents were similar between both blubber layers for the first two captures $(0.073<p<0.847)$ and became statistically higher in inner layer at week $7(p<0.001)$. Here again, the increase of $p, p^{\prime}$-DDE concentrations over the fast was more accentuated in inner blubber as compared to outer blubber $(0.001<p<0.038)$ (Fig. 3C).

\subsection{4. $H C B$}

HCB concentrations did not differ between the two blubber layers at each studied time $(0.132<p<0.475)$. The HCB concentrations increased slightly, but significantly, between early and late fast in both layers ( $p<0.001$ for the both blubber layers) (Fig. 3D).

Among all studied pollutants, PBDE and HCB concentrations were within the same order of magnitude in the blubber, whereas PCB and $p, p^{\prime}$-DDE concentrations were between one and two orders of magnitude higher. $p, p^{\prime}$-DDE concentrations were systematically the highest in all blubber samples.

\subsection{Changes of POPs in serum}

\subsubsection{PBDES}

The concentrations of total PBDEs in serum (expressed per unit of wet weight or per unit of lipid weight) increased significantly throughout the fasting period $(p<0.001)$ (Fig. 4 A and B). The dynamics of PBDEs were also expressed per unit of circulating NEFAs, as this lipid class directly reflects the lipolytic process and thus, the mobilisation of blubber triglycerides. Total serum PBDE concentrations expressed per unit of NEFAs dropped between weeks 1 and $4(p<0.001)$ before remaining constant until the end of the fast $(0.082<p<0.708)$. Concentrations at week $10 \mathrm{did}$ not statistically differ from those at week $1(p=0.145)$ (Fig. $4 C)$.

BDE-28, -153 and -154 were detected in only a few samples of serum (Table S2 in the Supplementary Information). No statistical test was thus performed with these congeners. BDE-47 was the major congener representing $96 \pm 4 \%$. When the results were expressed per unit of wet weight (Table 2), the concentrations of 
A

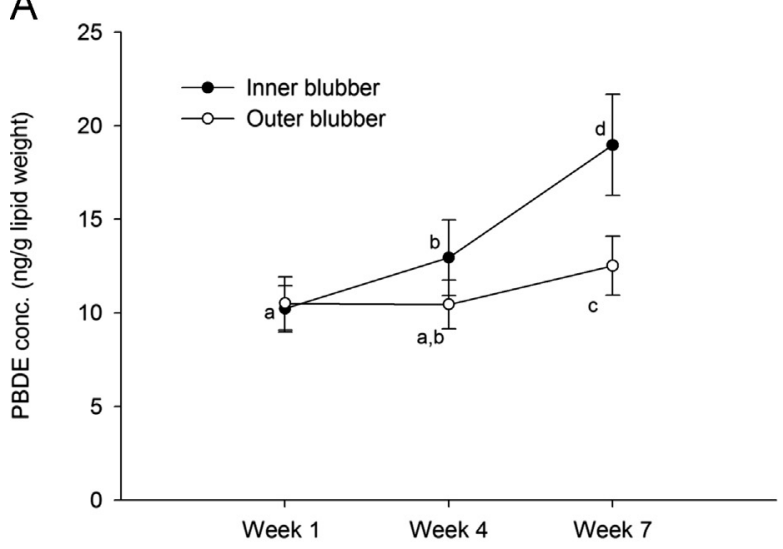

B

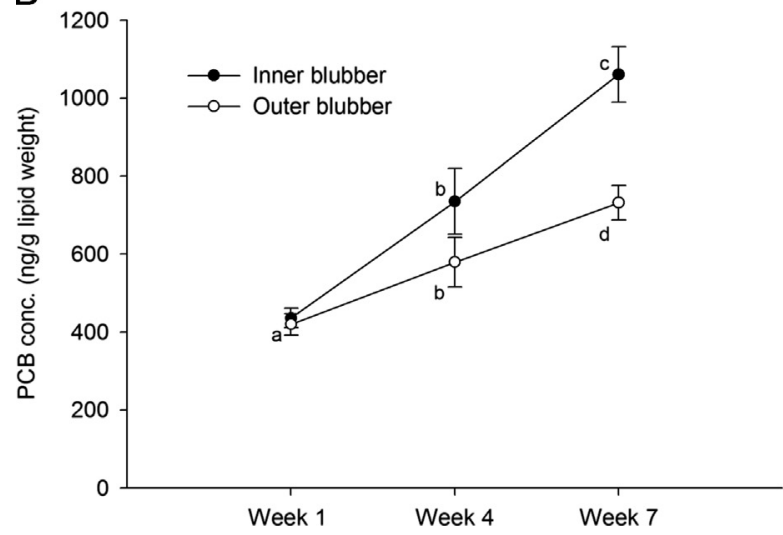

C
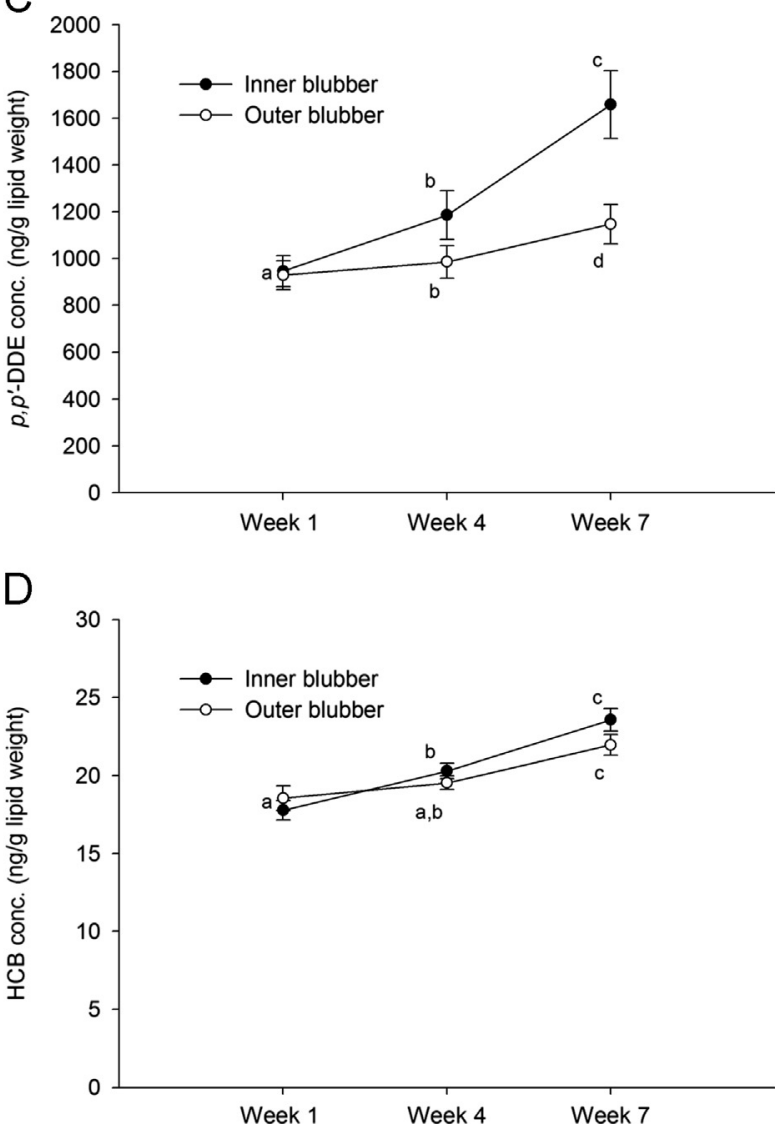

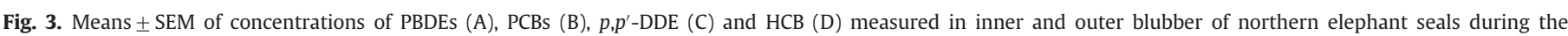
post-weaning fast (weeks 1,4 and 7 ). Values with different symbols are significantly different within a blubber layer as well as a defined time ( $p \leq 0.050$ ).

Table 2

Mean \pm SEM of levels of PBDE congeners, PCB classes, $p, p^{\prime}$-DDE and HCB measured in outer and inner blubber layers as well as serum of weaned NES pups.

\begin{tabular}{|c|c|c|c|c|c|c|c|c|c|c|}
\hline & \multicolumn{3}{|c|}{ Outer blubber (ng/g lipid weight) } & \multicolumn{3}{|c|}{ Inner blubber (ng/g lipid weight) } & \multicolumn{4}{|c|}{ Serum (pg/mL wet weight) } \\
\hline & Week 1 & Week 4 & Week 7 & Week 1 & Week 4 & Week 7 & Week 1 & Week 4 & Week 7 & Week 10 \\
\hline BDE-47 & $8.4 \pm 1.2^{\mathrm{a}}$ & $8.6 \pm 1.1^{\mathrm{a}}$ & $10.4 \pm 1.3^{\mathrm{b}}$ & $8.5 \pm 1.0^{\mathrm{a}}$ & $10.7 \pm 1.6^{\mathrm{b}}$ & $15.4 \pm 2.2^{\mathrm{c}}$ & $66.3 \pm 10.2^{\mathrm{a}}$ & $81.8 \pm 11.2^{\mathrm{b}}$ & $93.3 \pm 12.5^{\mathrm{c}}$ & $102.5 \pm 12.7^{\mathrm{d}}$ \\
\hline BDE-99 & $0.6 \pm 0.1^{\mathrm{a}, \mathrm{b}}$ & $0.4 \pm 0.1^{\mathrm{a}}$ & $0.6 \pm 0.1^{\mathrm{b}}$ & $0.4 \pm 0.1^{\mathrm{a}}$ & $0.6 \pm 0.1^{\mathrm{b}}$ & $1.0 \pm 0.1^{\mathrm{c}}$ & $2.3 \pm 1.6^{\mathrm{a}}$ & $0.5 \pm 0.2^{\mathrm{b}}$ & $2.3 \pm 0.3^{a}$ & $1.3 \pm 0.9^{\mathrm{a}}$ \\
\hline BDE-100 & $0.7 \pm 0.1^{\mathrm{a}}$ & $0.8 \pm 0.2^{\mathrm{a}}$ & $0.9 \pm 0.2^{\mathrm{b}}$ & $0.8 \pm 0.2^{\mathrm{a}}$ & $1.0 \pm 0.3^{b}$ & $1.5 \pm 0.4^{\mathrm{c}}$ & $3.5 \pm 1.1^{\mathrm{a}}$ & $1.7 \pm 1.0^{\mathrm{b}}$ & $1.0 \pm 1.6^{\mathrm{b}}$ & $3.0 \pm 1.3^{\mathrm{a}}$ \\
\hline BDE-154 & $0.7 \pm 0.1^{\mathrm{a}}$ & $0.6 \pm 0.1^{\mathrm{a}}$ & $0.6 \pm 0.1^{\mathrm{a}}$ & $0.6 \pm 0.6^{\mathrm{a}}$ & $0.7 \pm 0.1^{\mathrm{b}}$ & $0.9 \pm 0.9^{c}$ & N.D & N.D & N.D & N.D \\
\hline$\sum$ PBDEs & $11 \pm 1^{a}$ & $10 \pm 1^{a}$ & $13 \pm 2^{b}$ & $10 \pm 1^{a}$ & $13 \pm 2^{b}$ & $19 \pm 3^{c}$ & $72 \pm 11^{a}$ & $84 \pm 13^{b}$ & $97 \pm 14^{c}$ & $107 \pm 15^{d}$ \\
\hline$\sum$ tri-CBs & $4 \pm 1^{\mathrm{a}}$ & $3 \pm 1^{a}$ & $4 \pm 1^{\mathrm{a}}$ & $3 \pm 1^{\mathrm{a}, \mathrm{b}}$ & $2 \pm 0^{a}$ & $3 \pm 1^{\mathrm{b}}$ & $149 \pm 23^{a}$ & $173 \pm 26^{\mathrm{a}}$ & $5 \pm 3^{b}$ & $12 \pm 8^{c}$ \\
\hline$\sum$ tetra-CBs & $5 \pm 1^{a}$ & $6 \pm 2^{b}$ & $6 \pm 1^{c}$ & $5 \pm 1^{a}$ & $7 \pm 2^{\mathrm{b}}$ & $9 \pm 2^{c}$ & $130 \pm 55^{\mathrm{a}, \mathrm{c}}$ & $153 \pm 61^{a}$ & $69 \pm 13^{b}$ & $90 \pm 26^{c}$ \\
\hline$\sum$ penta-CBs & $112 \pm 8^{a}$ & $154 \pm 17^{\mathrm{b}}$ & $192 \pm 12^{\mathrm{c}}$ & $11 \overline{5} \pm 7^{\mathrm{a}}$ & $193 \pm 22^{b}$ & $273 \pm 18^{c}$ & $1033 \pm 48^{\mathrm{a}}$ & $1392 \pm 77^{b}$ & $1644 \pm 81^{c}$ & $1934 \pm 115^{d}$ \\
\hline$\sum$ hexa-CBs & $218 \pm 13^{a}$ & $302 \pm 23^{b}$ & $380 \pm 33^{c}$ & $226 \pm 12^{\mathrm{a}}$ & $382 \pm 44^{\mathrm{b}}$ & $556 \pm 37^{c}$ & $1642 \pm 69^{a}$ & $1979 \pm 90^{\mathrm{b}}$ & $2602 \pm 126^{\mathrm{c}}$ & $2961 \pm 174^{\mathrm{d}}$ \\
\hline$\sum$ hepta-CBs & $64 \pm 5^{a}$ & $93 \pm 12^{b}$ & $126 \pm 8^{c}$ & $68 \pm 4^{a}$ & $249 \pm 93^{b}$ & $184 \pm 13^{b}$ & $381 \pm 30^{\mathrm{a}}$ & $363 \pm 18^{a}$ & $529 \pm 33^{b}$ & $572 \pm 41^{\mathrm{b}}$ \\
\hline Eocta-CBs & $1.3 \pm 0.3^{\mathrm{a}}$ & $1.9 \pm 0.3^{\mathrm{b}}$ & $2.3 \pm 0.4^{c}$ & $1.4 \pm 0.2^{\mathrm{a}}$ & $2.9 \pm 0.8^{b}$ & $4.5 \pm 0.9^{c}$ & N.D & N.D & N.D & N.D \\
\hline$\sum$ PCBs & $419 \pm 27^{a}$ & $579 \pm 63^{b}$ & $732 \pm 45^{c}$ & $436 \pm 25^{a}$ & $735 \pm 85^{b}$ & $1060 \pm 71^{c}$ & $3723 \pm 172^{a}$ & $4533 \pm 246^{b}$ & $5058 \pm 248^{c}$ & $5851 \pm 348^{d}$ \\
\hline$p, p^{\prime}$-DDE & $928 \pm 62^{a}$ & $986 \pm 69^{b}$ & $1147 \pm 84^{c}$ & $946 \pm 66^{a}$ & $1186 \pm 104^{b}$ & $1658 \pm 145^{c}$ & $7416 \pm 636^{a}$ & $10609 \pm 872^{b}$ & $12514 \pm 979^{c}$ & $14628 \pm 996^{\mathrm{d}}$ \\
\hline HCB & $19 \pm 1^{a}$ & $20 \pm 1^{a}$ & $22 \pm 1^{b}$ & $18 \pm 1^{a}$ & $20 \pm \mathbf{1}^{b}$ & $24 \pm 1^{c}$ & $168 \pm 12^{a}$ & $309 \pm 14^{b}$ & $253 \pm 16^{c}$ & $430 \pm 29^{d}$ \\
\hline
\end{tabular}

For a defined tissue, values within a row followed by different letters are significantly different $(p \leq 0.05)$.

N.D $=$ not detected.

BDE-47 increased in the serum throughout the fast $(p<0.001)$, while the concentrations of BDE-99 and -100 remained stable ( $p=0.550$ and $p=0.452$, respectively) between early and late fast. Similar tendencies were observed when individual PBDEs were expressed per unit of serum lipids (Table S4 in the Supplementary Information). On the other hand, when expressed per unit of circulating NEFAs, levels of BDE-47, -99 and -100 decreased significantly between weeks 1 and $4(p<0.001)$ before remaining constant (BDE-47 and -99$)(p=0.061$ and $p=0.911$, respectively) or increasing slightly $(\mathrm{BDE}-100)(p<0.001)$ until the end of the fast (Table S4 in the Supplementary Information).

\subsection{2. $P C B S$}

Total PCB levels (expressed per unit of wet weight or per unit of lipid weight) rose in serum throughout the studied period 

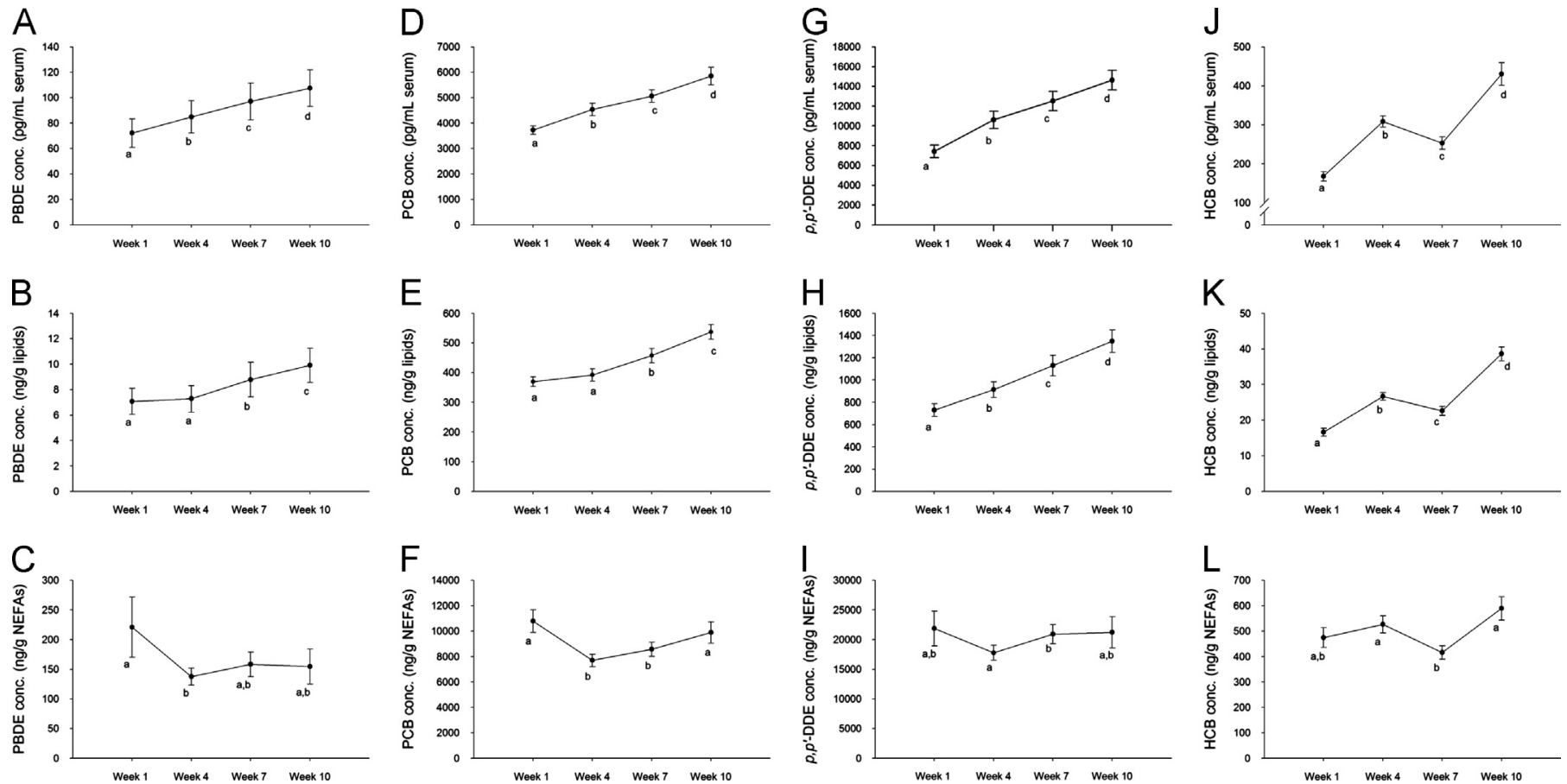

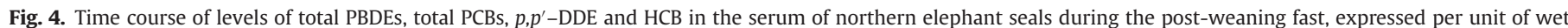

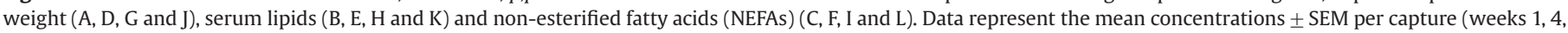
7 and 10). Values with different letters are significantly different $(p \leq 0.050)$.

$(p<0.001)$ (Fig. 4D and E). When the results were expressed per unit of circulating NEFAs, total PCB concentrations dropped between weeks 1 and $4(p<0.001)$ and then slightly increased between weeks 4 and 10 ( $p=0.012$ ). Like for total PBDEs, concentrations at week 10 did not statistically differ from those at week 1 $(p=0.463)$ (Fig. 4F).

Within PCB groups, octa-CBs (PCB-194 and-199), nona-PCB (PCB-206) and deca-CB (PCB-209) were measured in only a few samples (Table S3 in Supplementary Information). As a result, these congeners were not included in statistical analyses. In serum, we found mainly hexa-CBs (PCB-128, -138, -146, -149, $-151,-153$ and -156$)$, followed by penta-CBs (PCB-95, $-99,-101$, $-105,-110$ and -118$)$, tetra-CBs (PCB-47, $-49,-52,-74)$ and heptaCBs (PCB-170, -171, -174, -177, -180, -183, -187) for the first part of the fast and hexa-CBs followed by penta-CBs, hepta-CBs and then tetra-CBs for the second part of the fast. Similar to blubber, PCB-28 was the only congener constituting the tri-CB class. The class of tetra-CBs was composed of PCB-74 $(50 \pm 18 \%)$ followed by PCB-47 $(27 \pm 6 \%)$. The main congeners in the penta-CB class were PCB-99 (35 $\pm 2 \%)$ and PCB-118 (46 $\pm 1 \%$ ). PCB-153 formed almost one half of hexa-CB congeners ( $44 \pm 1 \%$ ) and PCB-138, one third (36 $\pm 0 \%$ ). Finally, two congeners were predominant in the group of heptaCBs: PCB-180 (34 $\pm 1 \%$ ) and PCB-187 (36 $\pm 1 \%$ ).

When the results were expressed per unit of wet weight, triCBs decreased significantly between weeks 1 and $10(p<0.001)$ and tetra-CBs remained constant $(p=0.085)$. The concentrations of penta-, hexa- and hepta-CBs increased significantly between early and late fast $(p<0.001)$ (Table 2$)$. When the levels of PCBs were expressed per unit of serum lipids, tri- and tetra-CBs decreased between weeks 1 and $10(0.001<p<0.026)$, whereas penta-, hexa- and hepta-CBs increased $(0.001<p<0.005)$ (Table S4 in Supplementary Information). When the different classes of PCBs were expressed per unit of circulating NEFAs, the levels of tri- and tetra-CBs decreased between weeks 1 and $10(p<0.001)$. The concentrations of penta-, hexa- and hepta-CBs dropped between weeks 1 and $4(0.001<p<0.035)$, then rose significantly between weeks 4 and $7(0.001<p<0.016)$ before remaining stable until week $10(0.291<p<0.751)$.

\subsection{3. $p, p^{\prime}-D D E$}

Similar to previous studied pollutants, $p, p^{\prime}$-DDE levels increased significantly during the fast of NES when the results were expressed per unit of wet weight and per unit of lipid weight $(p<0.001)$ (Fig. 4G and H). p, $p^{\prime}$-DDE concentrations expressed per unit of NEFAs remained constant between weeks 1 and $10(p=0.977)$ (Fig. 4I).

\subsection{4. $H C B$}

The HCB levels increased significantly between early and late fast when the results were expressed either per unit of wet weight or per unit of lipid weight $(p<0.001)$ (Fig. $4 \mathrm{~J}$ and $\mathrm{K}$ ). When expressed per unit of NEFAs, the concentrations of HCB did not differ between weeks 1 and 10 ( $p=0.070$ ) (Fig. 4L).

Similarly to blubber, serum of weaned NES pups was mainly contaminated by $p, p^{\prime}$-DDE and PCBs across the fasting period. Their concentrations were two orders of magnitude higher than those of PBDEs and HCB. Here again, $p, p^{\prime}$-DDE concentrations were systematically the highest in all samples.

\subsection{Comparisons of POP profiles between tissues}

\subsubsection{PBDES}

There was no significant difference of PBDE profile between outer and inner blubber, for a considered period $(0.062<$ $p<0.998$ ). The proportion of BDE-47 was lower in inner blubber than in serum at each studied period $(p<0.001)$, while the proportions of BDE-100 and -154 were higher in inner blubber than in serum at each studied period $(p<0.001)$. The proportions of BDE-99 were also higher in inner blubber than in serum $(p<0.001)$, except at week 1 where the proportions were similar between these two compartments $(p=0.723)$ (Fig. 5A). 
A

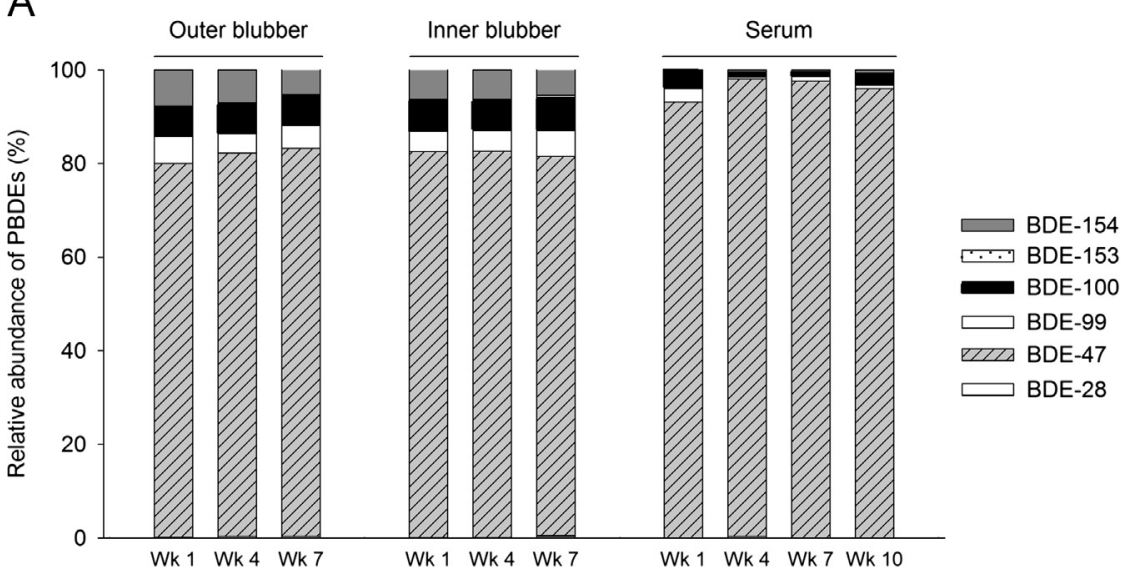

B
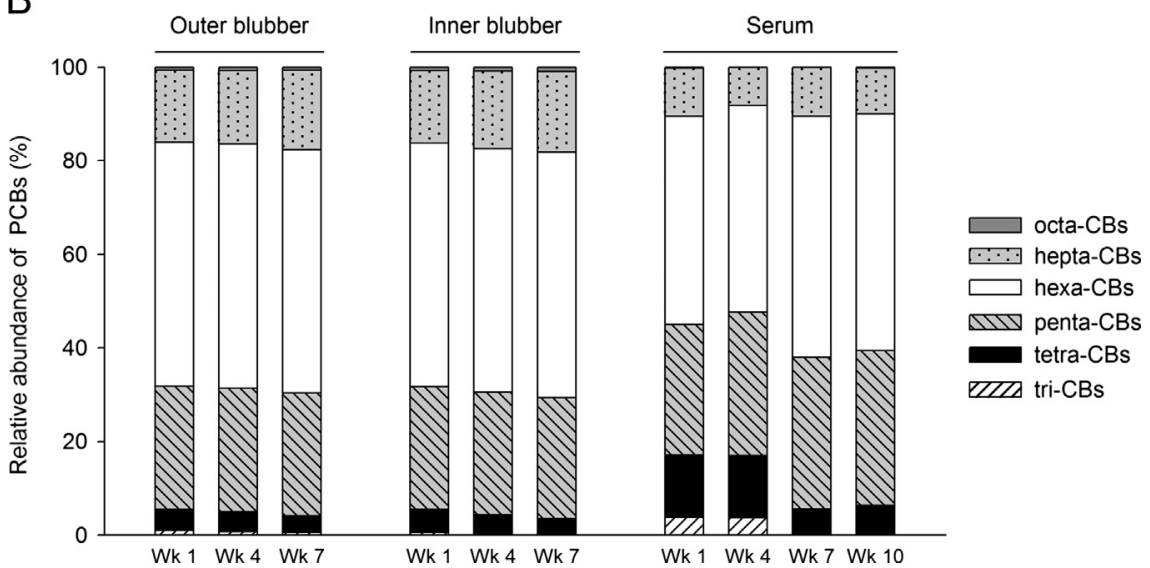

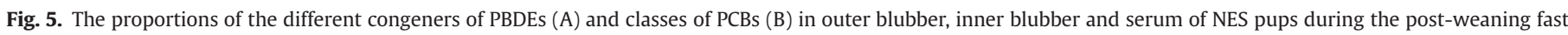
(weeks 1, 4, 7 and 10).

\subsection{2. $P C B s$}

For a considered period within the post-weaning fast (weeks 1 , 4 or 7), no significant difference was noted in the proportions of each class of PCBs between outer and inner blubber $(0.109<p<0.998)$. The percentages of tri-, tetra- and penta-CBs were lower in inner blubber compared to serum $(p<0.001)$, whereas those of hexaand hepta-CBs were higher in inner blubber compared to serum $(p<0.001)$ (Fig. 5B).

\subsection{Transfer ratios of POPs from blubber to serum}

The transfer ratios (TR) from inner blubber to serum, which correspond to the ratio of concentrations between serum and inner blubber decreased with the number of chlorine and bromine atoms within a period of fast (weeks 1, 4 and 7) for studied PBDE congeners and PCB classes (Fig. 6A and B). Furthermore, an inverse correlation was observed between the logarithm transformation of TR from inner blubber to serum and the $\log K_{\text {ow }}$ values. This was noticed at each studied period of fast (weeks 1, 4 and 7). These results suggest an exponentially decreasing relationship between TR and $\log K_{\text {ow }}$ values. No relationships were found for $p, p^{\prime}$-DDE and HCB (results not shown).

\section{Discussion}

This is the first study that monitors and compares the levels, profiles and dynamics of PBDEs, PCBs, $p, p^{\prime}$-DDE and HCB in the blubber and serum of NES pups throughout the post-weaning fast.

\subsection{Levels and profiles of pollutants}

Concentrations of targeted lipophilic groups measured in the weaned NES were in the order $p, p^{\prime}$-DDE $>$ PCBs $\gg$ HCB $>$ PBDEs

\subsubsection{PBDEs}

Weaned NES pups were marginally contaminated by PBDEs. The only other study investigating PBDE concentrations in NES focused on young (less than 1 year old), stranded individuals from southern California. The total blubber PBDE concentrations were 20-30 times higher than in the present study (Meng et al., 2009). The stranded animals used in Meng et al. (2009) were sampled from 1994 to 2006, just before they died. The cause of death and the degree of emaciation may influence the concentrations of PBDEs and thus explain, at least partly, the higher concentrations observed in their study. One must also note that 4-16 years separate the sampling of the two studies. The lower PBDE concentrations reported in our study might thus also be interpreted as a potential temporal trend as already observed in harbour seals near Vancouver Island (Ross et al., 2013). The drop of concentrations was explained by the withdrawal of the Pentaand Octa-BDE mixtures from the market in 2004 (Ross et al., 2013). Further investigations are however needed to confirm this hypothesis for NES.

NES weaned pups were also less contaminated by PBDEs (one order of magnitude) than weaned harbour seal pups from central California. Higher levels of contamination are also reported in marine mammals from other parts of the world, such as in harbour 



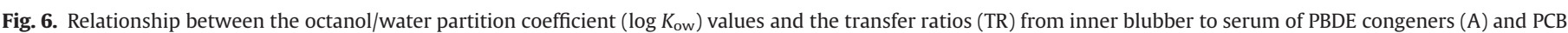

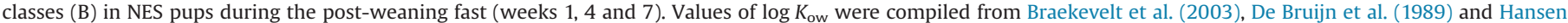
et al. (1999). Log $K_{\text {ow }}$ for the different classes of PCBs was calculated as the mean of log $K_{\mathrm{ow}}$ of each PCB congener present in the corresponding group.

seals from northwestern North America (one order of magnitude) (Ross et al., 2013) and from northwest Atlantic coast (one to two orders of magnitude) (Shaw et al., 2012) and in grey seals from Scotland (one order of magnitude) (Vanden Berghe et al., 2012).

The PBDE profile of weaned NES was mainly composed of BDE-47. This congener is usually the dominant PBDE congener in marine mammals (Meng et al., 2009; Vanden Berghe et al., 2012). The high proportion of BDE-47 could be explained by different factors, such as the importance of this congener, together with BDE-99, in the Penta-BDE industrial mixture, widely used in the 1990s and 2000s (deWit, 2002), the ability of marine mammals to debrominate BDE-99 into BDE-47 (Meng et al., 2009; Stapleton et al., 2004) and the higher bioaccumulation potential of lower brominated congeners (She et al., 2002).

\subsection{2. $P C B S$}

Total PCB levels reported in the present study were similar to the concentrations measured in the blubber of weaned NES pups sampled in the same colony in 2002 (Debier et al., 2005a, 2006). There was thus no temporal change of PCB concentrations in the blubber of NES weaned pups from Año Nuevo colony between 2002 and 2010. The PCB concentrations were also comparable to the data of healthy free-ranging yearling NES sampled in 1992 in California (Beckmen et al., 1997). Similar concentrations were also seen between 1997 and 2002 for NES pups along the Californian coast (Blasius and Goodmanlowe, 2008). In addition, NES weaned pups were contaminated within the range of PCB values encountered in NES lactating females from the same colony, most likely as a consequence of the efficient transfer through the milk (Debier et al., 2012).

Other data about PCBs in NES concern stranded/diseased NES pups and yearlings sampled in the 1990s and early 2000s. Levels reported in those studies are between 2 and more than 50 times higher than those reported in the present study (Beckmen et al., 1997; Blasius and Goodmanlowe, 2008; Kajiwara et al., 2001; Kannan et al., 2004). Such higher levels most probably result from the fact that those animals were not in good condition. Indeed, emaciation induces the concentration of pollutants within the remaining amount of blubber. In addition, during their first year of life, NES feed in the polluted coastal waters and do not gain much weight, leading to a concentration of pollutants in the adipose tissue. Their contamination thus rather reflects coastal pollution as compared to weaned pups and adult females (Debier et al., 2005a). The higher levels could also come, at least in part, from a prospective temporal trend, as a consequence of the reduction of $\mathrm{PCB}$ input since 1976 in USA and since 1977 in Canada. Data collected from the 1970s to the 1990s indicate decreasing levels of PCBs in the blubber of pinnipeds and cetaceans from the Pacific coast (Aguilar et al., 2002). Nevertheless, the fact that the PCB concentrations reported in NES healthy yearlings in 1992 were comparable to those of the present study indicates that body condition rather than temporal trend is the main factor involved in the higher concentrations observed in stranded/diseased NES.

Higher PCB concentrations (around one order of magnitude) are usually reported in the tissues of marine mammals from the Pacific coast of North America, such as live-captured harbour seals near Vancouver Island (Ross et al., 2013) and harbour seal pups from central California (Greig et al., 2011). In general, higher PCB levels (around one order of magnitude) are also found in marine mammals from other parts of the world, such as lactating grey seals from Scotland (Vanden Berghe et al., 2012) and harbour seals from Canada (Cullon et al., 2012).

The penta-, hexa- and hepta-CBs were the major components of the PCB content, as previously observed in NES from the same colony (Debier et al., 2005a, 2006, 2012), with CB-99, -118, -138 and -153 being the biggest contributors to the burden of PCBs.

\subsection{3. $p, p^{\prime}-D D E$}

The levels of $p, p^{\prime}$-DDE in the blubber of weaned NES, which makes up more than 98\% of total DDT (Debier et al., 2012; Greig et al., 2011; Vanden Berghe et al., 2012), were lower than the levels of total DDT previously reported in stranded yearling NES in 1990s and 2002 (Beckmen et al., 1997; Kajiwara et al., 2001; Kannan et al., 2004). As already explained for PCBs, a combination of coastal feeding habits, poor body condition and temporal trends are most probably at the origin of the higher total DDT levels reported in those studies. On the contrary, the total DDT concentrations encountered in the blubber of lactating females from the same colony were comparable to the present results, which reflects the high transfer of $p, p^{\prime}$-DDE from mother to pup through the consumption of milk (Debier et al., 2012). The high DDE/PCBs ratio reported in NES weaned pups is a common pattern of contamination on the west coast of North America (Debier et al., 2005a, 2012). More generally, the contamination of NES weaned pups was similar to the one of adult female grey seals from Scotland (Vanden Berghe et al., 2012) and higher than adult male and female Weddell seals from Antarctica (Trumble et al., 2012).

\subsection{4. $H C B$}

The concentrations of HCB were in the same order of magnitude as those found in earlier investigations on stranded yearling 
NES in California (Kajiwara et al., 2001; Kannan et al., 2004). There are also similar to those of lactating grey seals sampled in Canada (Sørmo et al., 2003) and harp seals sampled in Canada (Frouin et al., 2012), but slightly higher than those of lactating grey seals sampled in Scotland (Vanden Berghe et al., 2012).

\subsection{Dynamics of POPs throughout the fast}

During 6 weeks of post-weaning fast, weaned NES lost more than $30 \mathrm{~kg}$. Their lipid mass is reduced from $24-49 \%$ (Noren et al., 2003). Blubber lipids, which are mainly composed of triglycerides, are thus mobilised in high amounts during that period (Ryg et al., 1988). The mobilisation occurs mainly from the inner blubber layer, while the outer blubber layer remains relatively stable (Vanden Berghe et al., 2012; Wheatley et al., 2008). In the present study, constant lipid percentage per unit of weight was observed in inner blubber between early and late fast. Similar tendency was also highlighted in the blubber of NES lactating females (Crocker et al., 2001). Such results were however different from those of Vanden Berghe et al. (2012), for lactating grey seals, in which a small, but significant drop of blubber lipid percentage was seen. Adipocytes of fasting NES pups appear to shrink with the hydrolysis of triglycerides and the mobilisation of NEFAs in the circulation. Indeed, morphometric results showed an increase of small-size adipocytes as well as a decrease of mid- and large-size adipocytes in the blubber. In addition, there was a corresponding rise of circulating NEFAs throughout the post-weaning fast. The proportion of connective tissue being very small in phocid seals in general (1-4\%), it might explain the fact that the lipid percentage, expressed per unit of blubber weight, did not change significantly with the progression of the fast, despite the important triglyceride mobilisation.

At early fast, the concentrations of PBDEs, PCBs and $p, p^{\prime}$-DDE were homogeneously distributed in the blubber. Similar results were already observed for PCBs in the blubber of weaned NES (Debier et al., 2006). During suckling, NES pups accumulate a large fat deposit through the lipid-rich milk and lipophilic pollutants are distributed evenly throughout the adipose tissue. The onset of pollutant stratification within the blubber column may occur during the first fasting period (i.e. the post-weaning fast) and could be maintained throughout the life of adult animals by the numerous "feeding/fasting" cycles (Debier et al., 2006). PCB and DDT concentrations of NES lactating females are indeed characterised by a stratification between inner and outer blubber (Debier et al., 2012), a pattern also observed in other phocid seal species (Debier et al., 2003; Vanden Berghe et al., 2012). The concentrations of PBDEs, PCBs and $p, p^{\prime}$-DDE expressed per unit of blubber lipids of weaned NES rose throughout the fast. The phenomenon was more pronounced in inner blubber, probably because of the higher mobilisation of lipids from this layer. As a result, POP concentrations became higher in inner blubber as compared to outer blubber at late fast. This suggests a more efficient and prominent mobilisation of lipids than POPs from blubber, as already shown in weaned NES (Debier et al., 2006). It is possible that such lipophilic pollutants preferentially remain within the adipose tissue and/or are released into the circulation and then reabsorbed by adipocytes, as a result of their affinity for this lipophilic compartment (Vanden Berghe et al., 2012).

Within PCB groups, the increase of concentrations appeared to vary with the chlorination degree of the congeners, especially in inner blubber. The rise of concentrations was indeed more pronounced for more lipophilic compounds such as octa- and hepta-CBs, followed by hexa- and penta-CBs, followed by tetraand tri-CBs. It suggests that the mobilisation of POPs from blubber is influenced, at least in part, by the physico-chemical properties of the molecules (molecular weight, size and lipophilicity) (Vanden
Berghe et al., 2012). By way of example, the mean $\log K_{\text {ow }}$ for hepta-CBs is 7.0 (range: 6.93-7.17), which can therefore be considered as extremely lipophilic, whereas the $\log K_{\text {ow }}$ for triCBs (represented by PCB-28) is 5.55, which reflects a less lipophilic character. The higher chlorinated, and thus more lipophilic, congeners concentrate more importantly in the blubber with the progression of the fast than the lower chlorinated congeners.

Furthermore, it should be noted that the behaviour of HCB was slightly different from the ones of PBDEs, PCBs and $p, p^{\prime}$-DDE. It was homogeneously distributed in the blubber at early fast and increased slightly, over the course of fast, in both layers. It seems that HCB $\left(\log K_{\text {ow }}=5.47\right.$; Gobas et al., (1988)) does not concentrate in inner blubber lipids as dramatically as the other POP families. HCB dynamic could thus be compared to the behaviour of lower chlorinated PCBs, especially to tri- $\left(\log K_{\text {ow }}\right.$ for PCB-28 $\left.=5.55\right)$ and tetra-CBs (mean $\log K_{\mathrm{ow}}=5.9$; range: $5.86-6.01$ ). Due to their less pronounced lipophilic character, they seem to be more easily mobilised from blubber into the serum.

An increase in concentration of POPs was noted in the serum of weaned NES throughout the fast, when the results were expressed per unit of wet weight and per unit of lipid weight. Since blubber is the main storage site of POPs (Wolkers et al., 2006), it is reasonable to assume that the contamination of serum would depend in part on the mobilisation of POPs from the inner layer, which is more vascularised and metabolically active. As already noted above, POPs may be mobilised from blubber into the bloodstream together with lipids. One part of the discharged POPs might then be reabsorbed by the blubber, while the other part is put into circulation by the blood flow (Vanden Berghe et al., 2012). Serum NEFAs increase significantly across the fast in weaned pups but this increase may be strongly influenced by changes in rates of re-esterification instead of enhanced lipolysis (Viscarra and Ortiz, 2013). When the POP levels were expressed per unit of serum NEFAs, the concentrations of PBDEs and PCBs dropped between weeks 1 and 4, before stabilizing until the end of the fast. These dynamics support the hypothesis that the mobilisation of POPs from adipose tissue is less important than the one of lipids especially during the first part of the fast, but rises at the end of the fast (Debier et al., 2003, 2006).

Within PCB groups, the dynamics of tri- and tetra-CBs differed from those of other congeners and from the general tendency discussed here above. Their levels, expressed per unit of wet weight, lipid weight and NEFAs, decreased during the second part of the fast. It is possible that those congeners, once mobilised into the circulation, are efficiently taken up by other tissues such as the liver and biotransformed. Indeed, marine mammals appear to be capable of biotransforming PCBs to some extent, through the production of CYPs in the phase I biotransformation process (Nyman et al., 2001; Teramitsu et al., 2000). More investigations are needed to warrant this hypothesis on the biotransformation of tri- and tetra-CBs in NES pups.

\subsection{Comparisons of POP composition between tissues}

The PBDE and PCB profiles were fairly stable within the blubber layers. Otherwise, the pattern of the inner blubber differed from that of serum. Indeed, the lower halogenated congeners (BDE-47, a tetra-BDE, and tetra- and penta-CBs) were present in higher proportions in serum, whereas the higher halogenated congeners (two penta-BDEs: BDE-99 and -100; a hexa-BDE: BDE-154; together with hexa- and hepta-CBs) were found in higher proportions in the inner blubber. Such pattern supports the selective retention of some congeners in inner blubber. The TR of PBDE congeners and $\mathrm{PCB}$ classes from inner blubber to serum was indeed inversely related to their water solubility $\left(\log K_{\text {ow }}\right)$, which agreed with previous findings on the mobilisation of PCBs and 
PBDEs from the blubber of lactating grey seals (Vanden Berghe et al., 2012). This tendency has been also observed during weight loss in humans (Dirtu et al., 2013). The less lipophilic contaminants (with low $\log K_{\mathrm{ow}}$ ) were more efficiently mobilised from inner blubber to serum than the more lipophilic ones (with high $\log K_{\text {ow }}$ ).

It is reasonable to think that the mobilisation of POPs is affected by the lipid composition of both compartments. Phocid blubber lipids contain more than $99 \%$ of non-polar triglycerides (Wheatley et al., 2008), while circulating blood lipids consist of non-polar triglycerides, but also NEFAs, cholesterol, cholesterol esters and phospholipids (Sørmo et al., 2003). The most apolar POPs would thus preferentially remain in the adipose tissue.

\section{Conclusions}

With the exception of $\mathrm{HCB}$, the weaned NES pups were characterised by a relatively low contamination as compared to the levels usually found in the literature on marine mammals. Nevertheless, the significant release of POPs from blubber to serum during the post-weaning fast may cause a potential risk for the health of such young animals, which undergo a crucial period of development. We observed a homogeneous distribution of POPs throughout the blubber at early fast in NES weaned pups. At late fast, the concentrations of PBDEs, PCBs and $p, p^{\prime}$-DDE were higher in inner than in outer blubber, as a result of the sharp increase of their levels in the inner layer with the progression of the fast. These findings could be explained by a more efficient mobilisation of lipids from adipose tissue as compared to POPs. The behaviour of POPs was influenced by the physico-chemical properties of the molecules: the higher halogenated POPs (i.e. the more lipophilic congeners) were preferentially kept within blubber with the progression of the fast than the lower halogenated congeners.

\section{Funding sources}

Part of this work was supported by the financial support of the Belgian National Council for Scientific Research (FNRS - Fonds associés - FRFC) (Grant no. FC55682/2.4.502.07F). Caroline Louis has received a grant from Fonds A. De Potter (Académie Royale de Belgique - Classe des Sciences). Krishna Das is a F.R.S.-FNRS Research Associate. Alin C Dirtu and Govindan Malarvannan acknowledge post-doc fellowships from the Flanders Funds for Scientific Research (Project 5261) and the University of Antwerp (Project 5014), respectively.

\section{Acknowledgements}

The authors are very grateful to Sarah Habran, Betsy Kelso, Mike Tift and Segal Boaz as well as the 2010 field team from Sonoma State University and University of California, Santa Cruz for the fieldwork support. We also thank the Año Nuevo Rangers for their cooperation. Rose-Marie Goebbels from UCLouvain is gratefully acknowledged for the histological techniques. Research was conducted under the National Marine Fisheries Service Marine Mammal Permit \#87-1743-05.

\section{Appendix A. Supporting information}

Supplementary data associated with this article can be found in the online version at http://dx.doi.org/10.1016/j.envres.2014.04.016.

\section{References}

Aguilar, A., et al., 2002. Geographical and temporal variation in levels of organochlorine contaminants in marine mammals. Mar. Environ. Res. 53, 425-452.

Beckmen, K., et al., 1997. Clinical and pathological characterization of northern elephant seal skin disease. J. Wildl. Dis. 33, 438-449.

Blasius, M.E., Goodmanlowe, G.D., 2008. Contaminants still high in top-level carnivores in the Southern California Bight: levels of DDT and PCBs in resident and transient pinnipeds. Mar. Pollut. Bull. 56, 1973-1982.

Braekevelt, E. et al., 2003. Direct measurement of octanol-water partition coefficients of some environmentally relevant brominated diphenyl ether congeners. Chemosphere 51, 563-567.

Covaci, A., et al., 2002a. Distribution of organobrominated and organochlorinated contaminants in Belgian human adipose tissue. Environ. Res. 88, 210-218.

Covaci, A., et al., 2008. Anthropogenic and naturally occurring organobrominated compounds in two deep-sea fish species from the Mediterranean Sea. Environ. Sci. Technol. 42, 8654-8660.

Covaci, A., et al., 2002b. Determination of organohalogenated contaminants in liver of harbour porpoises (Phocoena phocoena) stranded on the Belgian North Sea coast. Mar. Pollut. Bull. 44, 1157-1165.

Crocker, D.E., et al., 2001. Maternal traits and reproductive effort in northern elephant seals. Ecology 82, 3541-3555.

Cullon, D.L., et al., 2012. Biomagnification of polychlorinated biphenyls in a harbor seal (Phoca vitulina) food web from the strait of Georgia, British Columbia, Canada. Environ. Toxicol. Chem. 31, 2445-2455.

Darnerud, P.O., 2008. Brominated flame retardants as possible endocrine disrupters. Int. J. Androl. 31, 152-160.

Das, K., et al., 2006. Interfollicular fibrosis in the thyroid of the harbour porpoise: An endocrine disruption? Arch. Environ. Contam. Toxicol. 51, 720-729.

De Bruijn, J., et al., 1989. Determination of octanol/water partition coefficients for hydrophobic organic chemicals with the "slow-stirring" method. Environ. Toxicol. Chem. 8, 499-512.

de Wit, C.A., 2002. An overview of brominated flame retardants in the environment. Chemosphere 46, 583-624.

Debier, C., et al., 2006. Mobilization of PCBs from blubber to blood in northern elephant seals (Mirounga angustirostris) during the post-weaning fast. Aquat Toxicol. 80, 149-157.

Debier, C., et al., 2012. Differential changes of fat-soluble vitamins and pollutants during lactation in northern elephant seal mother-pup pairs. Comp. Biochem. Physiol. Part A: Mol. Integr. Physiol. 162, 323-330.

Debier, C., et al., 2005a. Polychlorinated biphenyls, dioxins, and furans in weaned, free-ranging northern elephant seal pups from central California, USA. Environ. Toxicol. Chem. 24, 629-633.

Debier, C., et al., 2003. Quantitative dynamics of PCB transfer from mother to pup during lactation in UK grey seals Halichoerus grypus. Mar. Ecol. Prog. Ser. 247, 237-248.

Debier, C., et al., 2005b. PCBs and DDT in the serum of juvenile California sea lions: associations with vitamins A and E and thyroid hormones. Environ. Pollut. 134, 323-332.

Dirtu, A.C., et al., 2013. Dynamics of organohalogenated contaminants in human serum from obese individuals during one year of weight loss treatment. Environ. Sci. Technol. 47, 12441-12449.

Frouin, H., et al., 2012. Transfer of PBDEs and chlorinated POPs from mother to pup during lactation in harp seals Phoca groenlandica. Sci. Total Environ. 417, 98-107.

Gobas, F.A.P.C., et al., 1988. A novel method for measuring membrane-water partition coefficients of hydrophobic organic chemicals: comparison with 1-octanol-water partitioning. J. Pharm. Sci. 77, 265-272.

Greig, D.J., et al., 2011. Geography and stage of development affect persistent organic pollutants in stranded and wild-caught harbor seal pups from central California. Sci. Total Environ. 409, 3537-3547.

Hansen, B.G., et al., 1999. QSARs for $K_{\mathrm{OW}}$ and $K_{\mathrm{OC}}$ of PCB congeners: a critical examination of data, assumptions and statistical approaches. Chemosphere 39, 2209-2228.

Jürgens, M.D., et al., 2013. The presence of EU priority substances mercury, hexachlorobenzene, hexachlorobutadiene and PBDEs in wild fish from four English rivers. Sci. Total Environ. 461, 441-452.

Kajiwara, N., et al., 2001. Organochlorine pesticides, polychlorinated biphenyls, and butyltin compounds in blubber and livers of stranded California sea lions, elephant seals, and harbor seals from coastal California, USA. Arch. Environ. Contam. Toxicol, 41, 90-99.

Kannan, K., et al., 2004. Organochlorine pesticides and polychlorinated biphenyls in California sea lions. Environ. Pollut. 131, 425-434.

Letcher, R.J., et al., 2010. Exposure and effects assessment of persistent organohalogen contaminants in arctic wildlife and fish. Sci. Total Environ. 408, 2995-3043.

Meng, X.Z., et al., 2009. Polybrominated diphenyl ethers in pinnipeds stranded along the Southern California coast. Environ. Pollut. 157, 2731-2736.

Mossner, S., et al., 1994. Determination of HCHs, PCBs, and DDTs in brain tissues of marine mammals off different age. Fresenius' J. Anal. Chem. 349, 708-716.

Noren, D.P., et al., 2003. Energy reserve utilization in northern elephant seal (Mirounga angustirostris) pups during the postweaning fast: size does matter. J. Comp. Physiol. B: Biochem. Syst. Environ. Physiol. 173, 443-454.

Nyman, M., et al., 2001. Characterization of xenobiotic-metabolizing cytochrome P450 (CYP) forms in ringed and grey seals from the Baltic Sea and reference sites. Comp. Biochem. Physiol. Part C: Toxicol. Pharmacol. 128, 99-112. 
Ross, P.S., 2002. The role of immunotoxic environmental contaminants in facilitating the emergence of infectious diseases in marine mammals. Hum. Ecol. Risk Assess.: Int. J. 8, 277-292.

Ross, P.S., et al., 2013. Declining concentrations of persistent PCBs, PBDEs, PCDEs, and PCNs in harbor seals (Phoca vitulina) from the Salish Sea. Prog. Oceanogr. $115,160-170$.

Ryg, M., et al., 1988. Thermal significance of the topographical distribution of blubber in ringed seals (Phoca hispida). Can. J. Fish. Aquat. Sci. 45, 985-992.

Severinsen, T., et al., 2000. Spatial distribution of persistent organochlorines in ringed seal (Phoca hispida) blubber. Mar. Environ. Res. 49, 291-302.

Shaw, S.D., et al., 2012. Tissue-specific accumulation of polybrominated diphenyl ethers (PBDEs) including Deca-BDE and hexabromocyclododecanes (HBCDs) in harbor seals from the Northwest Atlantic. Environ. Int. 44, 1-6.

She, J., et al., 2002. PBDEs in the San Francisco Bay area: measurements in harbor seal blubber and human breast adipose tissue. Chemosphere 46, 697-707.

Sørmo, E.G., et al., 2003. Partitioning of persistent organic pollutants in grey seal (Halichoerus grypus) mother-pup pairs. Sci. Total Environ. 302, 145-155.

Stapleton, H.M., et al., 2004. Debromination of polybrominated diphenyl ether congeners BDE 99 and BDE 183 in the intestinal tract of the common carp (Cyprinus carpio). Environ. Sci. Technol. 38, 1054-1061.

Teramitsu, I., et al., 2000. Identification of novel cytochrome P450 1A genes from five marine mammal species. Aquat. Toxicol. 51, 145-153.
Trumble, S.J., et al., 2012. Assessment of legacy and emerging persistent organic pollutants in Weddell seal tissue (Leptonychotes weddellii) near McMurdo Sound, Antarctica. Sci. Total Environ. 439, 275-283.

Vanden Berghe, M., et al., 2010. Relationships between vitamin A and PCBs in grey seal mothers and pups during lactation. Environ. Pollut. 158, 1570-1575.

Vanden Berghe, M., et al., 2012. Selective transfer of persistent organic pollutants and their metabolites in grey seals during lactation. Environ. Int. 46, 6-15.

Viscarra, J.A., Ortiz, R.M., 2013. Cellular mechanisms regulating fuel metabolism in mammals: role of adipose tissue and lipids during prolonged food deprivation. Metabolism 62, 889-897.

Weijs, L., et al., 2009. Concentrations of chlorinated and brominated contaminants and their metabolites in serum of harbour seals and harbour porpoises. Environ. Int. 35, 842-850.

Wheatley, K.E., et al., 2008. Differential mobilization of blubber fatty acids in lactating Weddell seals: evidence for selective use. Physiol. Biochem. Zool. 81 651-662.

Wolkers, H., et al., 2006. Tissue-specific accumulation and lactational transfer of polychlorinated biphenyls, chlorinated pesticides, and brominated flame retardants in hooded seals (Cistophora cristata) from the Gulf of St. Lawrence: applications for monitoring. Environ. Pollut. 142, 476-486.

Ylitalo, G.M., et al., 2005. The role of organochlorines in cancer-associated mortality in California sea lions (Zalophus californianus). Mar. Pollut. Bull. 50, 30-39. 